\title{
Sclero-atrophic lichen of unusual siege that occurred during the Pregnancy
}

\author{
A Rasso*, K Laamari, S Benkirane, A Oulhri, H Baybay, Z.Douhi, S.Elloudi, Fz Mernissi \\ Department of Dermatology, CHU Hassan II de Fez, Morocco
}

*Corresponding author: A Rasso, Department of Dermatology, CHU Hassan II de Fez, Morocco, E-mail: rassoasmae@gmail.com

\section{Keywords: Sclero-atrophic lichen; Pregnancy; Breasts}

Received Date: November 18, 2019; Accepted Date: November 30, 2019; Published Date: December 07, 2019

\section{Clinical Image}

A 35-year-old women, without a significant pathological history, she reported the notion of lesions appearing when she was pregnant at 30 weeks of amenorrhea in the breasts, slightly itchy and evolving since one year. The dermatological examination found pigmented sclero-atrophic plaques on the breasts (Figure 1). Dermoscopy showed a globular pattern and telangiectasia (Figure 2). The rest of the clinical examination was normal. The diagnosis of extra-genital sclero-atrophic lichen was retained by histology. The biological check-up including hepatitis B and C serologies was normal and treated by emollients and dermocorticoids. The evolution was marked by the disappearance of pruritus and persistence of pigmented scars.

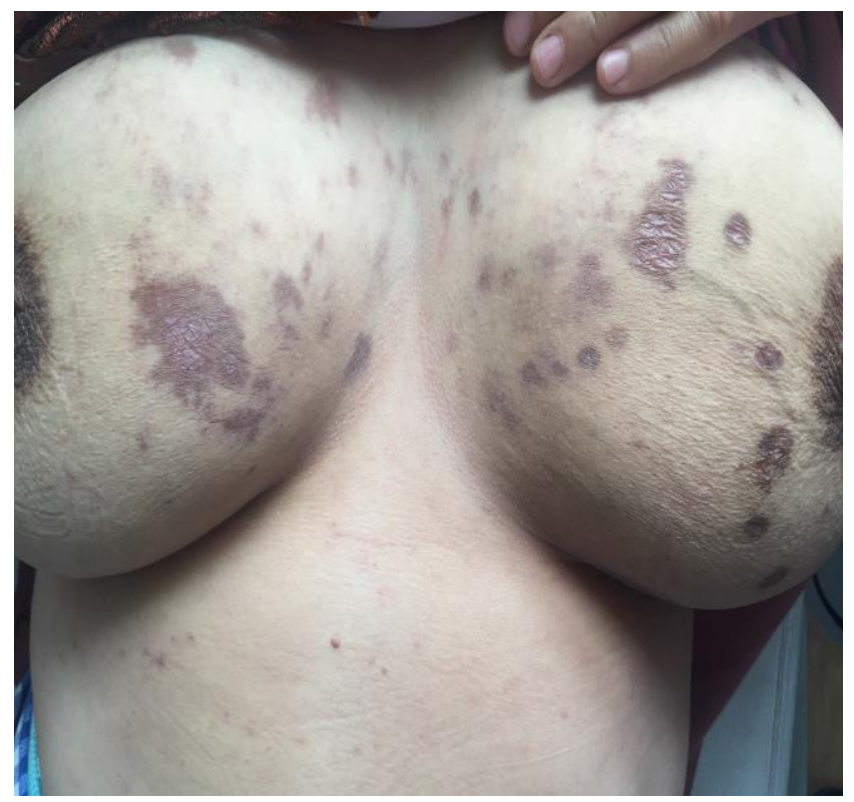

Figure 1: Atrophic pigmented plaques of the breasts.

Citation: A Rasso, Sclero-atrophic lichen of unusual siege that occurred during the Pregnancy. J Clin Cases Rep 3(4): 150151. 


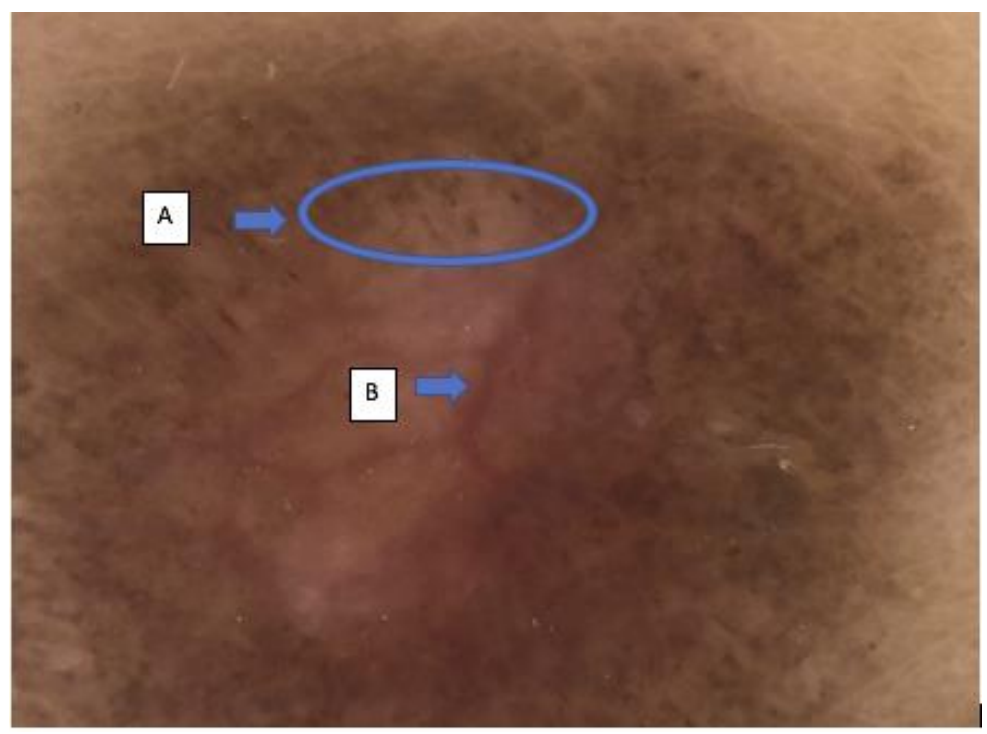

Figure 2: (A) Globular pattern; (B) telangiectasia.

Sclerous or sclero-atrophic lichen (SAL) is a fibrotic inflammatory dermatosis of chronic evolution and female predominance, affecting mainly the ano-genital region (80\%). Purely extragenital localization is seen in only $2.5 \%$ of cases [1]. Pathophysiology would involve several hormonal, genetic (HLA II DQ7), infectious (Borrelia burgdorferi) or traumatic factors by Köebner phenomenon. Clinically, it manifests itself as whitish or pearly white sometimes pigmented, atrophic plaques, mainly affecting the trunk, the root of the limbs and the folds. Pruritus is inconsistent. Diffuse forms are rare. The breast damage noted in our patient has rarely been reported in the literature and could be explained by the köebner caused by breast distension or hormonal factors [2]. The diagnosis is based on skin histology. The processing is not codified. It may include: dermocorticoids, synthetic antimalarial drugs, Tacrolimus, Retinoids, Calcipotriol and UVB phototherapy. Our patient was treated by a dermocorticoid alone with a clear improvement.

\section{References}

1. Sellami K, Masmoudi A, Mseddi M, et al. (2018) Cutaneous sclero-atrophic lichen (8 cas). Annals of Dermatology and Venereology 145 (4): A52.

2. Vujovic O (2010) Lichen sclerosus in a radiated breast. Canadian Medical Association Journal 182(18): E860. 